\title{
Vermicomposto bioenriquecido com Trichoderma spp.
}

\author{
Vermicompost bioenriched whit Trichoderma spp.
}

\section{Cleudson José Michelon', Lethícia Rosa Neto², Pâmela Oruoski², Marília Boff de Oliveira², Caroline Castilhos Vieira ${ }^{3}$ \& Emanuele Junges ${ }^{1^{*}}$}

\footnotetext{
${ }^{1}$ Instituto Federal Farroupilha, São Vicente do Sul, RS, Brasil. *Autor para correspondência: emanuele.junges@iffarroupilha.edu.br.

${ }^{2}$ Universidade Federal de Santa Maria, Santa Maria, RS, Brasil.

${ }^{3}$ Instituto Federal Farroupilha, Júlio de Castilhos, Brasil, RS.
}

Submissão: 05/03/2017 | Aceite: 30/10/2017

\begin{abstract}
RESUMO
A ciclagem de resíduos de origem animal pelo processo de compostagem e sua transformação em insumos para produção vegetal além de minimizarem os impactos ambientais, podem ser uma importante fonte de renda ao produtor. Além disso, a compostagem desses resíduos produz um insumo agrícola com elevado potencial na produção de hortaliças e com possibilidade de associação com organismos de controle biológico, possibilitando a produção de um substrato ecologicamente correto, rico em nutrientes e protetor da saúde das plantas. Nesse sentido, o objetivo deste trabalho foi avaliar a sobrevivência do fungo Trichoderma spp. durante o processo de vermicompostagem, as alterações físico/químicas ocasionadas no substrato e o crescimento e desenvolvimento de plantas de alface cultivadas. Foram avaliados, como substratos base, resíduos da criação de ovinos; cavalos e coelhos, com ou sem a adição de Trichoderma spp. Em todos os tratamentos foram adicionadas minhocas da espécie Eisenia fetida. Os tratamentos foram arranjados em esquema fatorial $3 \times 2$ e 0 delineamento experimental foi 0 inteiramente casualizado, com 4 repetições $O$ fungo Trichoderma spp. sobrevive durante o processo de vermicompostagem dos diferentes resíduos. A utilização de Trichoderma spp. não teve efeito nos teores de fósforo, magnésio e matéria orgânica, reduziu os valores de cálcio, elevou os teores de potássio para o substrato a base de coelho, aumentou a densidade seca do substrato base de resíduos de coelho e reduziu do substrato base de resíduos de cavalos. O substrato que proporcionou o melhor crescimento e desenvolvimento de plantas de alface foi o de resíduos de criação de cavalos, sendo favorecido pela presença de Trichoderma spp. no segundo ano de cultivo.
\end{abstract}

PALAVRAS-CHAVE: fertilizantes orgânicos, Eisenia foetida, compostagem.

\begin{abstract}
The intensification of agropastoral activity leads to a high production of waste. The composting of these residues produces an agricultural input with high potential in the production of vegetables and with the possibility of association with organisms of biological control, allowing the production of an ecologically correct substrate, rich in nutrients and protector of the health of the plants. In this sense, the objective of this work was to evaluate the survival of the fungus Trichoderma spp. During the vermicompost process, as the physical / chemical development caused not substrate and the growth and development of lettuce plants grown in the different treatments used. Basal substrates were obtained from the creation of three different animals: sheep, Horses and rabbits, whether or not containing added Trichoderma spp. In all treatments, worms of Eisenia foetida were added. Evaluations of fungus survival, physical and chemical analyzes of the substrate produced and evaluation without growth and development of lettuce plants were carried out. The treatments were arranged in a $3 \times 2$ factorial scheme and the experimental design was completely randomized, with 4 replicates. Data were analyzed using Sisvar ${ }^{\circledR}$ software, and as means averages compared by Scott Knott's test at $5 \%$ error probability. Trichoderma spp. It survives the vermicompost process by improving the development of lettuce plants when associated with farms residue. The use of Trichoderma spp. It reduced the calcium values of all substrates, raised a dry density of the base substrate of rabbit residues, and reduced the base substrate of farmyard residues. The substrate that provided the best growth and development of lettuce plants was the residues of rearing of horses, being favored by the presence of Trichoderma spp. in the second year.
\end{abstract}

KEYWORDS: organic fertilizers, Eisenia foetida, composting. 


\section{INTRODUÇÃO}

A intensa atividade agropastoril gera uma grande quantidade de resíduos e o seu descarte tem sido motivo de grande preocupação. O Rio Grande do Sul é conhecido pela intensificação dos sistemas de produção animal, necessitando de alternativas que minimizem os problemas ambientais decorrentes da atividade. Nesse sentido, a gestão e o tratamento adequado dos dejetos animais surgem como uma alternativa mitigadora desse processo.

A adoção de técnicas adequadas de gestão pode atenuar os riscos ambientais associados à produção de adubo de origem animal, estabilizando-o antes da sua utilização (LAZCANO et al. 2008). A vermicompostagem é um processo de degradação e estabilização do material orgânico, por meio da ação constante de minhocas e microrganismos (DOMINGUEZ 2004). Em geral, este processo é constituído por duas fases: (I) fase ativa das minhocas que processam o substrato, modificando seu estado físico e sua composição microbiana (LORES et al. 2006), e (II) fase de maturação, onde as minhocas se deslocam para camadas mais frescas de substrato não digerido, deixando os microrganismos assumirem o material processado pelas minhocas (AIRA et al. 2007). A duração da fase de maturação é influenciada pela composição do substrato e também pela densidade de minhocas que atuam sobre ele. Essa prática tem sido utilizada com muito sucesso para a estabilização desses materiais orgânicos ricos em nutrientes (BUSATO et al. 2012).

A horticultura também é uma atividade frequente em pequenas propriedades, na maioria dos casos complementando a produção de animais. Nesses casos, o armazenamento, para posterior reaproveitamento dos resíduos animais, é um recurso importante na diminuição de custos com a fertilização. Nesse aspecto a vermicompostagem é um processo que apresenta resultados positivos, utilizando a excelente capacidade que as minhocas possuem de transformar e reciclar os resíduos orgânicos. Esses benefícios se devem principalmente pela produção de húmus, que é um composto coloidal rico em nutrientes oriundo das dejeções das minhocas (AMORIM et al. 2005). Dessa maneira, a vermicompostagem produz um substrato mais evolutivo de mineralização e humificação e mais rico em nutrientes minerais (N, P e K) (COTTA et al. 2015).

Outra ferramenta que está sendo usada, associada ao substrato no cultivo de hortaliças, são os microrganismos benéficos, fungos e/ou bactérias, com destaque para algumas espécies do gênero de fungos Trichoderma. Alguns isolados de Trichoderma podem atuar no controle de fitopatógenos (BROTMAN et al. 2010) ou como estimuladores do crescimento vegetal, pela habilidade que possuem na solubilização de minerais, colocando-os disponíveis para as plantas, e também pela produção de análogos de auxinas (HARMAN 2000; VINALE et al. 2008). De acordo com ALTOMARE et al. (1999), os macro e os micronutrientes sofrem um equilíbrio dinâmico complexo de solubilização e insolubilização no solo, fortemente influenciado pelo $\mathrm{pH}$ e pela microflora, os quais afetam sua acessibilidade para absorção pelas raízes das plantas.

Considerando que as propriedades do vermicomposto, associadas à ação do fungo Trichoderma spp., podem influenciar positivamente no crescimento e no desenvolvimento de plantas de alface, este trabalho teve como objetivo avaliar a sobrevivência do fungo Trichoderma spp., após o processo de vermicompostagem, e as alterações físico/químicas ocasionadas no substrato pela presença deste microrganismo e pela promoção do crescimento e do desenvolvimento em plantas de alface.

\section{MATERIAL E MÉTODOS}

O experimento foi conduzido nos anos de 2015 e 2016 na área experimental do Instituto Federal

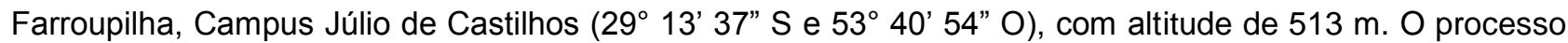
de vermicompostagem e o tratamento dos resíduos com Trichoderma foram realizados em minhocário de alvenaria com 24 repartições de dimensões de $1,0 \mathrm{~m}^{2}$ e $0,50 \mathrm{~m}$ de altura, coberto com telhas de amianto.

Os resíduos orgânicos utilizados como substrato base (SB) foram: 1) resíduos da criação de ovinos, compostos por fezes e urina; 2) resíduos da criação de cavalos, compostos por fezes, urina e casca de arroz; 3) resíduos da criação de coelhos, compostos por fezes, urina e restos de pelagem.

As minhocas matrizes utilizadas para a produção do vermicomposto foram da espécie Eisenia fetida. Colocou-se 100 gramas de minhocas para cada $5 \mathrm{~kg}$ de substrato base. Para a inoculação foi utilizado um produto comercial a base Trichoderma spp., com concentração de $48 \mathrm{~g}$ de Trichoderma por litro. A proporção utilizada foi de $1 \mathrm{~mL}$ de inóculo diluído em cada $10 \mathrm{~L}$ de resíduos de substrato base. A inoculação do substrato com o fungo Trichoderma spp. foi realizada através da incorporação da solução ao substrato, juntamente com a liberação das minhocas matrizes. 
Dessa forma, os tratamentos utilizados foram: T1: SB 1 sem inoculação de Trichoderma spp.; T2: SB 1 com inoculação de Trichoderma spp.; T3: SB 2 sem inoculação de Trichoderma spp; T4: SB 2 com inoculação de Trichoderma spp.; T5: SB 3 sem inoculação de Trichoderma spp. e T6: SB 3 com inoculação de Trichoderma spp.

Para a avaliação da sobrevivência de Trichoderma spp., durante os dois anos de avaliação, foram realizadas coletas em cinco diferentes pontos da pilha de material vermicompostado em cada compartimento do minhocário respectivo a cada tratamento. Dessas amostras foram realizadas diluições seriais do vermicomposto para a determinação da presença de Unidades Formadoras de Colônia (UFCs) viáveis de Trichoderma spp. Para isso, $5 \mathrm{~g}$ de amostras do vermicomposto de cada tratamento foram diluídas em $95 \mathrm{~mL}$ de água destilada e esterilizada, acrescida de duas gotas de Tween $80^{\circledR}$. Os frascos contendo a suspensão foram colocados em agitador do tipo Fisher - Flexa Mix ${ }^{\mathrm{TM}}$ (USA) por 10 minutos e, a partir dessa suspensão, foram feitas diluições seriais até o fator $10^{-4}$. Em seguida, $0,5 \mathrm{~mL}$ dessas diluições foram transferidas para placas de petri, com meio de cultura seletivo Martin, acrescido de $0,05 \mathrm{mg}$ de estreptomicina/100 mL de meio, e incubadas por cinco dias a $25{ }^{\circ} \mathrm{C}$ em fotoperíodo de 12 horas em incubadora do tipo BOD.

Foram realizadas análises física e química dos substratos produzidos, determinando-se as densidades úmida e seca e os teores de cálcio, de magnésio, de fósforo e de potássio, assim como de matéria orgânica. As densidades úmida e seca dos substratos foram determinadas pelo método de HOFFMANN (1970) e as análises químicas, conforme TEDESCO et al. (1995).

O substrato obtido foi acondicionado em embalagens plásticas de filme tubular $(15 \mathrm{~cm} \times 100 \mathrm{~cm})$, para cultivo de alface semi-hidropônico em bancadas. Para cada repetição foram colocadas três mudas de alface (Lactuca sativa) cultivar brisa. As plantas foram irrigadas por gotejamento de acordo com as necessidades hídricas da cultura.

Aos 45 dias após a semeadura, determinou-se a altura de plantas, o número de folhas por planta, o comprimento do sistema radicular e a massa verde e seca das plantas de alface. A altura de plantas foi obtida através da medida da base até o ápice de cada planta. Já o número de folhas, pela contagem das folhas de cada planta. A massa verde foi obtida através da pesagem das plantas e a massa seca após secagem em estufa de ventilação forçada à $65^{\circ} \mathrm{C}$ até massa constante. Para avaliação do comprimento de raiz, as embalagens plásticas foram abertas para retirada das plantas de forma cuidadosa, para que 0 máximo de raízes fosse preservado. Posteriormente o seu comprimento foi obtido por meio da medida do sistema radicular de cada planta. No ano seguinte, o experimento foi realizado novamente, preservando os mesmos substratos base, cultivar e época de cultivo, onde foram determinados a altura de plantas, 0 número de folhas por planta, o comprimento do sistema radicular e a massa seca de raízes e de folhas.

$O$ delineamento experimental foi $o$ inteiramente casualizado, os tratamentos foram arranjados em esquema fatorial $3 \times 2$ (substrato base $X$ inoculação de Trichoderma spp.), com 4 repetições. Os dados foram analisados utilizando o software Sisvar, e as médias comparadas pelo teste de Scott-Knott (FERREIRA 2011) a $5 \%$ de probabilidade de erro.

\section{RESULTADOS E DISCUSSÃO}

$\mathrm{Na}$ determinação de sobrevivência de Trichoderma spp., foi observado que todas as placas apresentavam crescimento do fungo. Isso possibilitou determinar que Unidades Formadoras de Colônia permaneceram viáveis em todos os substratos base utilizados, mostrando a possibilidade de serem utilizados em grande escala para a produção de substrato para o cultivo de mudas. KUBICEK et al. (2008) afirmam que o gênero Trichoderma prevalece em diferentes ecossistemas e em uma ampla gama de zonas climáticas.

O vermicomposto oriundo de substrato base da criação de ovinos com Trichoderma spp. foi aquele que apresentou a maior densidade úmida (Figura 1a). Para este vermicomposto, a utilização do fungo Trichoderma resultou em aumento de $7 \%$ na densidade úmida. Este resultado pode estar relacionado à composição do substrato (fezes + urina) e ao ambiente que ele proporcionou para o desenvolvimento do fungo. De acordo com BUClO et al. (2015), a inoculação de $T$ harzianum provocou aderência das hifas às raízes de tomate no meio liquido. Além disso, algumas espécies de Trichoderma liberam substâncias que podem contribuir para a estruturação de um substrato mais denso. No substrato a base da criação de coelho, houve uma redução de $12 \%$ da densidade úmida quando inoculado com Trichoderma, em relação ao não inoculado. Não houve efeito significativo da utilização do Trichoderma spp. na densidade úmida do substrato a base da criação de cavalos. 

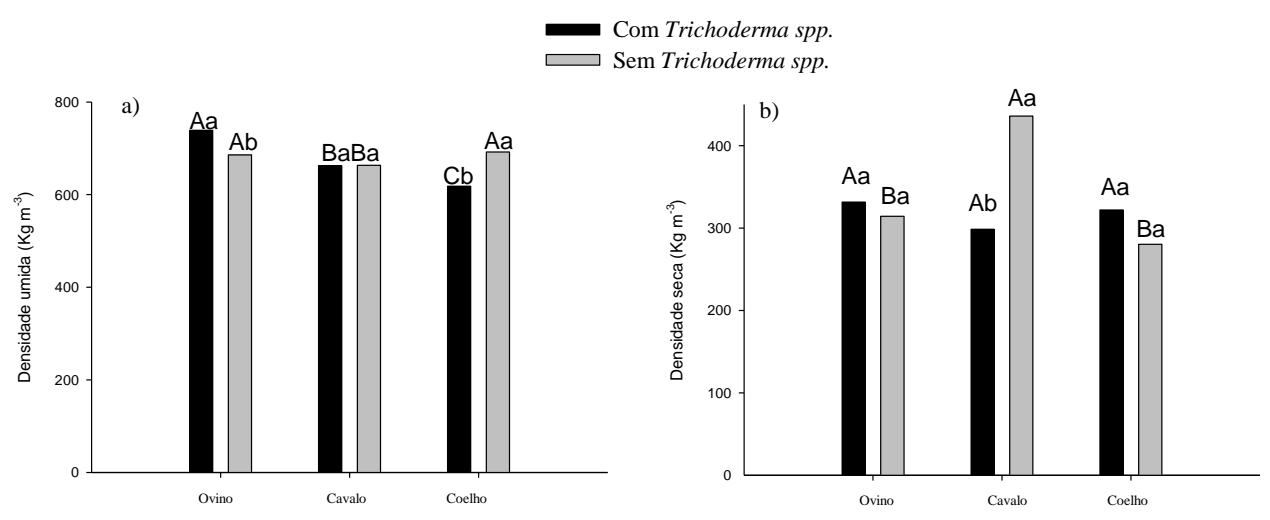

Figura 1. Densidade úmida (a) e Densidade seca (b) dos substratos base da criação de ovinos, cavalos e coelhos, com e sem Trichoderma spp. Médias seguidas por mesma letra maiúscula não diferem entre si entre os diferentes substratos. Médias seguidas por mesma letra minúscula não diferem entre si entre os tratamentos com e sem adição de Trichoderma spp. pelo teste de Scott-Knott $(p<0,05)$.

Figure 1. Density (a) and dry density (b) of the basic substrates of sheep, horse farms and rabbits rearing, with and without Trichoderma spp. Means followed by the same capital letter do not differ among the different substrates. Means followed by the same lowercase letter do not differ between treatments with and without addition of Trichoderma spp. by the Scott-Knott test $(p<0.05)$.

A combinação do fungo Trichoderma spp. e do vermicomposto resultou em um incremento de $15 \%$ na densidade seca do substrato base da criação de coelhos, com a adição de Trichoderma em relação ao tratamento sem o fungo e a redução de $46 \%$ na densidade seca do substrato base da criação de cavalos com adição de Trichoderma (Figura 1b). Os resultados para os tratamentos com e sem Trichoderma não foram significativos para o substrato a base de ovinos. O menor valor de densidade seca encontrado no substrato a base da criação de cavalos possivelmente está associado a sua estrutura composta por fezes, urina e casca de arroz, a qual possui uma alta relação $\mathrm{C} / \mathrm{N}$ e compostos recalcitrantes que permanecem por mais tempo no substrato, dificultando sua decomposição e favorecendo a porosidade dele.

Os resultados dos teores de cálcio $(\mathrm{Ca})$ e potássio $(\mathrm{K})$ apresentaram interação entre os substratos base e o fungo Trichoderma (Figura 2). Os teores de magnésio $(\mathrm{Mg})$, fósforo $(\mathrm{P})$ e matéria orgânica $(\mathrm{MO})$ apresentaram significância apenas para os diferentes substratos estudados (Figura 3). A associação do substrato base da criação de coelhos com Trichoderma causou uma redução de $26 \%$ no teor de cálcio (Ca). Para os demais substratos base estudados, a associação com Trichoderma não influenciou os teores desse nutriente (Figura 2c). Estes resultados estão de acordo com os encontrados por WIETHAN (2015), que observou uma redução dos valores de Ca a medida que aumentava a concentração de Trichoderma spp. no substrato. De acordo com SILVA \& AGUIAR (2001), TAMAI et al. (2002), GONZALEZ et al. (2009), alguns fungos decompositores e ectomicorrízicos, durante seu metabolismo, produzem ácido oxálico, que reage com o $\mathrm{Ca}$, ocorrendo a formação de cristais de oxalato de cálcio. Com isso, ocorre a redução do teor de $\mathrm{Ca}$ trocável do meio.

$\mathrm{O}$ teor de $\mathrm{K}$ do substrato a base da criação de cavalos não foi influenciado pela associação com o fungo Trichoderma spp. (Figura 2d). Entretanto observou-se um incremento de 38\% e de $9 \%$ nos teores de $\mathrm{K}$ dos substratos base de coelho e de ovino, respectivamente, quando associados ao fungo Trichoderma spp. (Figura 2). Resultados semelhantes foram obtidos por PRATES et al. (2007), que testaram a aplicação de Trichoderma spp. no substrato, a qual promoveu maior concentração de $\mathrm{K}$ nas folhas de mudas enxertadas de laranja. A associação do fungo com as minhocas pode ter influenciado de forma positiva a concentração de $\mathrm{K}$ no substrato.

Além disso, o maior teor de $\mathrm{K}$ no substrato a base da criação de coelho enriquecido com Trichoderma spp. pode estar associado à alta quantidade de $\mathrm{K}$ fornecida por este tratamento, pois este elemento é prontamente disponível às plantas quando fornecido por meio de adubos orgânicos (CQFS-RS/SC 2004). DURIGON et al. (2014) verificaram que o Trichoderma causou aumento significativo nos teores de $\mathrm{K}$ no tecido das plantas, sendo que houve um incremento de $58,7 \%$ em relação ao tratamento sem Trichoderma spp. 


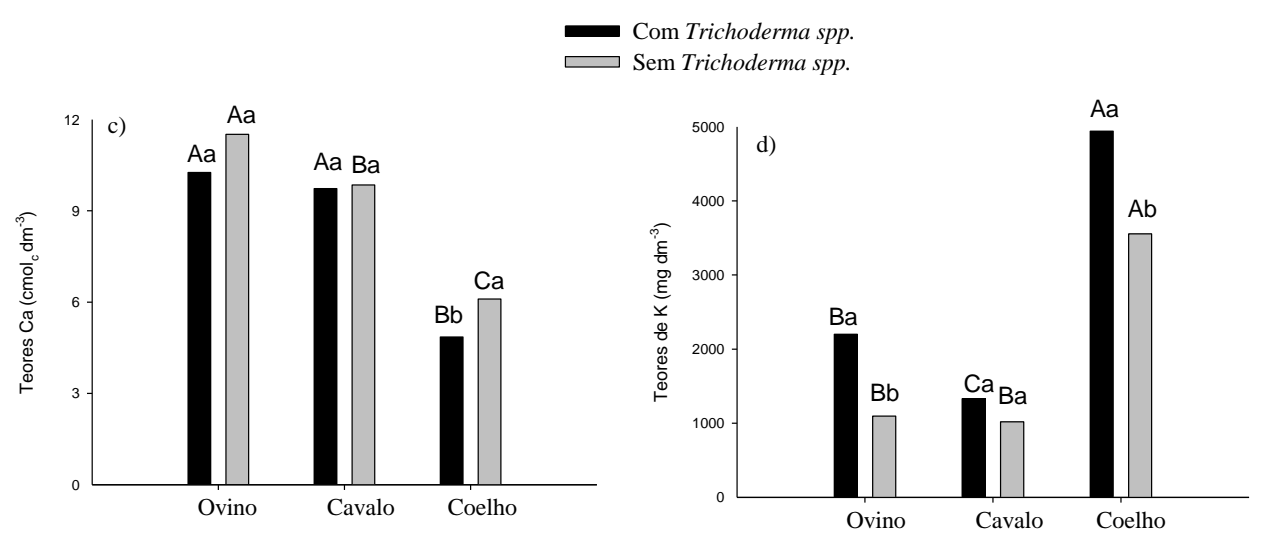

Figura 2. Teores de Cálcio (Ca) (c), e de potássio (K) (d), dos substratos base da criação de ovinos, cavalos e coelhos, com e sem Trichoderma spp. Médias seguidas por mesma letra maiúscula não diferem entre si entre os diferentes substratos. Médias seguidas por mesma letra minúscula não diferem entre si entre os tratamentos com e sem adição de Trichoderma spp. pelo teste de Scott-Knott $(\mathrm{p}<0,05)$.

Figure 2. Levels of calcium (Ca) (c), and potassium (K) (d), the substrate base of sheep, horse farms and rabbits with and without Trichoderma spp. Means followed by the same capital letter do not differ between the different substrates. Means followed by the same lowercase letter do not differ between treatments with and without addition of Trichoderma spp. by the Scott-Knott test $(p<0.05)$.
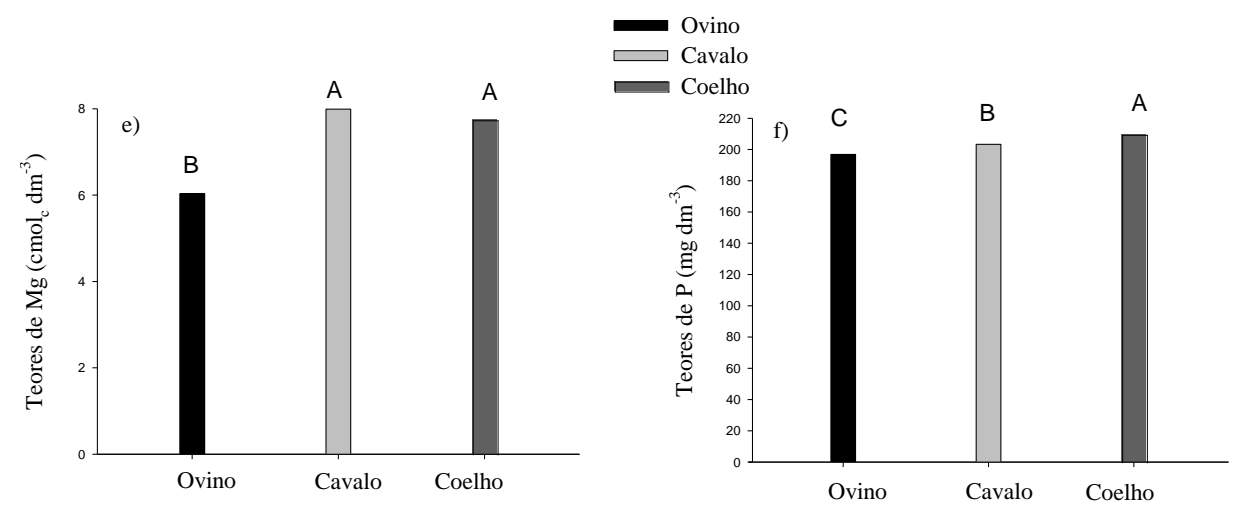

Figura 3. Teores de Magnésio (Mg) (e), e de fósforo (P) (f), dos substratos base da criação de ovinos, cavalos e coelhos, com e sem Trichoderma spp. Médias seguidas por mesma letra não diferem entre si pelo teste de Scott Knott $(p<0,05)$.

Figure 3. Levels of magnesium (Mg) (e), and phosphorus $(P)(f)$ of the substrate base of sheep, horse farms and rabbits with and without Trichoderma spp. Means followed by same letter do not differ by test by Scott Knott $(p<0.05)$.

Para os teores de $\mathrm{P}$ e $\mathrm{Mg}$, não houve efeito significativo do uso do Trichoderma spp. Em relação à concentração desses nutrientes, houve diferença apenas entre os diferentes substratos. Para o teor de $\mathrm{P} o$ substrato a base de criação de coelhos apresentou maior concentração, seguido do substrato base de criação de cavalos e ovinos (Figura 3f). No entanto, em estudos realizados por WIETHAN (2015), com Trichoderma spp. associado a esterco bovino na produção de alface, observou-se que a análise química da parte aérea das mudas de alface indicou maior porcentagem de $\mathrm{P}, \mathrm{K}, \mathrm{Ca}$ e $\mathrm{Mg}$ nos tratamentos em que se utilizou Trichoderma spp., quando comparados ao tratamento controle.

A distinção dos níveis de $\mathrm{P}$ entre os diferentes substratos e a insignificância do efeito do Trichoderma neste parâmetro podem estar associadas a suplementação dada aos animais. De acordo com MAENZ \& CLASSEN (1988), alguns animais, como porcos e galinhas, não utilizam, de forma eficiente, o $P$ predominantemente armazenado em grãos de cereais, o que acarreta uma diminuição do $P$ inorgânico, reduzindo a excreção de $P$ para o ambiente (WANG et al. 2005). Esse resultado também pode estar 
relacionado à estrutura do substrato, alterado pela ação das minhocas, causando elevação na concentração de $\mathrm{P}$, conforme verificado por MANSELL et al. (1981). SATCHELL \& MARTIN (1984) associaram esse comportamento à ação direta das enzimas intestinais das minhocas e, indiretamente, à estimulação da microflora e às bactérias com capacidade de solubilizar fosfatos. Além disso, a microflora influencia o nível de potássio disponível (GARD et al. 2006); neste estudo os maiores níveis foram verificados no substrato base de criação de coelhos e ovinos, diferente do de origem de criação de cavalos, o qual continha casca de arroz que possivelmente prejudicou a atuação das minhocas. As maiores concentrações de $\mathrm{Mg}$ resultaram dos substratos a base da criação de cavalos e coelho (Figura 3 e). Estes resultados corroboram os de BASSACO (2014), que constataram que o vermicomposto a base de resíduos de coelhos foi aquele que apresentou os maiores teores de N, P, K, Ca e Mg.

Os teores de Matéria Orgânica não foram influenciados pelo uso do Trichoderma, sendo as maiores concentrações encontradas no substrato a base de criação de ovinos, quando comparado aos demais substratos (Figura 4). Diferente desse estudo, BASSACO (2014) encontraram teor de carbono superior no substrato base da criação de coelhos em relação ao substrato base de criação de ovinos. No entanto, SOUZA et al. (2013) encontraram resultados semelhantes para a matéria orgânica do solo no tratamento em que se utilizou a relação 1:1:1 de esterco ovino, areia e solo.

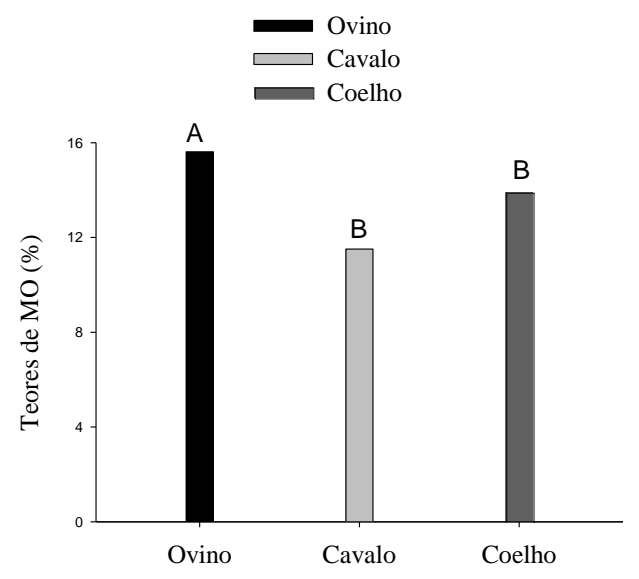

Figura 4. Teor de matéria orgânica, dos substratos base da criação de ovinos, cavalos e coelhos, com e sem Trichoderma spp. Médias seguidas por mesma letra não diferem entre si teste de Scott-Knott $(\mathrm{p}<0,05)$.

Figure 4. Levels of organic matter, of the base substrates of sheep, horse farms and rabbits, with and without Trichoderma spp. Averages followed by the same letter did not differ among them Scott-Knott test $(p<0.05)$.

O comprimento das raízes de plantas de alface apresentou comportamento distinto nos anos avaliados. No primeiro ano de execução do experimento, não houve interação entre os substratos base e o fungo Trichoderma spp. (Figura $5 \mathrm{~g}$ ). As plantas que se desenvolveram no substrato base de criação de cavalos apresentaram sistema radicular 35\% superior aos encontrados no substrato a base de criação de ovinos e $46 \%$ maior do que os encontrados na criação de coelhos. Tais resultados podem estar associados à composição do substrato (fezes + casca de arroz), onde a mistura dessa composição causou melhoria das características estruturais do composto, apresentando um valor intermediário de densidade úmida, proporcionado pela casca de arroz. A menor densidade do substrato favorece o desenvolvimento das plantas, melhorando a aeração e a drenagem e aumentando a capacidade de retenção de água (DINIZ et al. 2006).

No segundo ano de realização do experimento, observou-se a interação entre os substratos base e o fungo Trichoderma spp. (Figura 5h). A utilização do substrato base de criação de ovinos e o substrato de cavalos, associados com o fungo Trichoderma spp., resultou em aumento de $48 \%$ e $228 \%$, respectivamente, nas raízes de plantas de alface. Isso possivelmente se deve a melhor colonização do substrato pelo fungo e às alterações físicas ocorridas nos substratos utilizados, em especial na densidade 
seca do substrato base de criação de cavalos, quando este substrato foi usado em associação com o fungo Trichoderma spp.
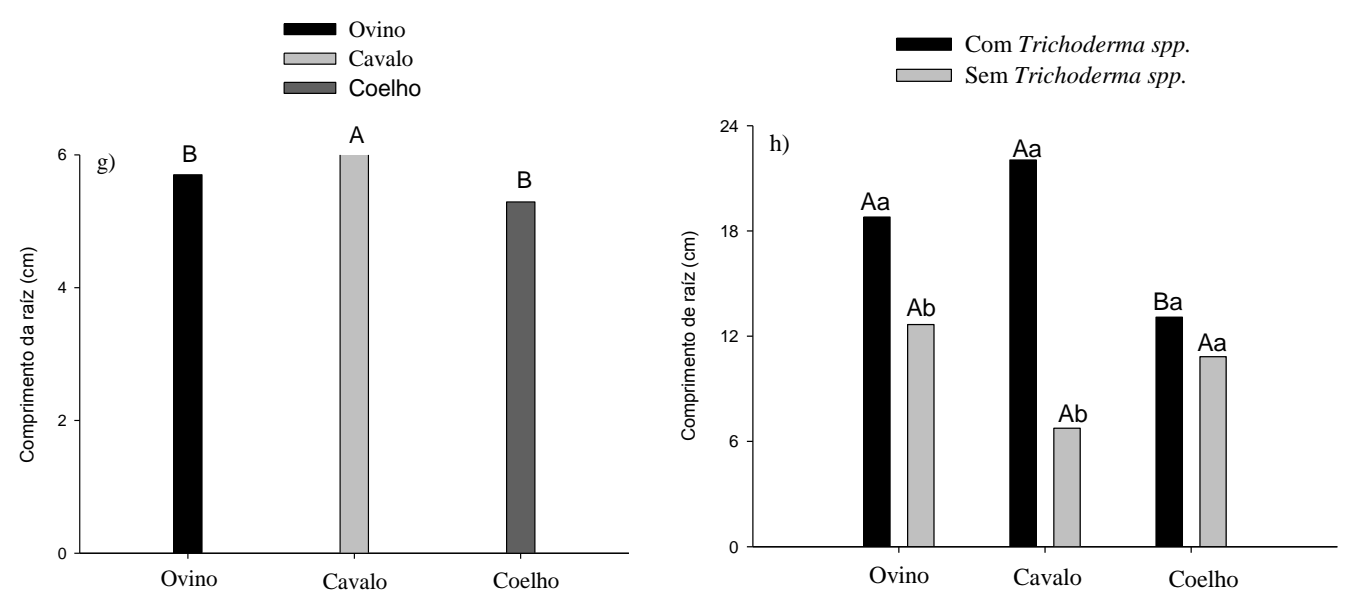

Figura 5. Comprimento de raízes de plantas de alface cultivadas em substratos base da criação de ovinos, cavalos e coelhos, com e sem Trichoderma spp. no primeiro ano de experimento (2015) (g); e (h), no segundo ano de experimento (2016). Médias seguidas por mesma letra maiúscula não diferem entre si entre os diferentes substratos. Médias seguidas por mesma letra minúscula não diferem entre si entre os tratamentos com e sem adição de Trichoderma pelo teste de Scott Knott $(p<0,05)$.

Figure 5. Root length of lettuce plants grown on the basis substrates of sheep, horse farms and rabbits, with and without Trichoderma spp., the first year of experiment (2015) (g).; and (h), in the second year of experiment (2016). Means followed by the same capital letter do not differ between the different substrates. Means followed by the same lowercase letter do not differ between treatments with and without addition of Trichoderma spp. by the Scott-Knott test $(p<0.05)$.

Ainda no segundo ano de experimento, a associação do substrato base de criação de coelhos com o fungo Trichoderma spp. não resultou em alteração no comprimento de raízes de alface, em comparação ao uso do substrato sem associação com o fungo. Tal resultado pode estar relacionado ao elevado valor de densidade seca apresentado pelo substrato, quando comparado aos outros substratos, que influencia 0 crescimento do fungo e o desenvolvimento do sistema radicular, devido à quantidade e ao tamanho das partículas que definem a aeração e a retenção de água (FERMINO 2003).

Para a altura de plantas (Figura 6), houve interação significativa entre os substratos base e o fungo Trichoderma spp., nos dois anos de condução do experimento. A utilização do substrato base de criação de ovinos, associado com o fungo, resultou em menor tamanho de plantas nos dois anos de condução do experimento. Essa redução foi de $32 \%$ no primeiro ano e de $20 \%$ no segundo ano.

A altura de plantas obtidas no substrato base de criação de coelhos, associado com o fungo Trichoderma spp., foi $25 \%$ menor no primeiro ano do experimento, quando comparada à altura de plantas conduzidas com o substrato base de criação de coelho sem o fungo (Figura 6i). Os valores elevados de K, encontrados no esterco de coelho, possivelmente influenciaram nos menores valores de altura de plantas encontrados neste estudo, pois a alta concentração do nutriente ocasiona salinidade afetando o crescimento das plantas (ARAÚJO NETO et al. 2009).

No segundo ano de condução do experimento, a associação de substrato base da criação de coelho com o fungo Trichoderma spp., não influenciou no tamanho de plantas de alface. Essa mesma resposta foi observada para o substrato base de criação de cavalos, nos dois anos de condução do experimento (Figura 6j). Resultados semelhantes foram encontrados por WIETHAN (2015), os valores de altura de plantas de alface com Trichoderma spp., após 28 dias da semeadura, foram inferiores ao controle. De acordo com JONES et al. (1988), algumas espécies de Trichoderma produzem fitotoxinas, como por exemplo o viridiol, o qual tem efeito retardante no desenvolvimento de mudas de alface.

O número de folhas por plantas apresentou comportamento distinto nos dois anos de condução do experimento. No primeiro ano, não houve interação entre os substratos base e fungo Trichoderma spp. $O$ número de folhas por plantas foi $11 \%$ e $9 \%$ mais elevado nos substratos base da criação de cavalos e de ovinos, respectivamente, em comparação ao substrato base da criação de coelhos (Figura 7k). Esses 
resultados estão de acordo com os encontrados por MORALES et al. (2013), em que, ao utilizarem vermicomposto com incremento de casca de arroz em sua composição no cultivo de alface, obtiveram maior número de folhas, quando comparados aos tratamentos sem a presença deste material.

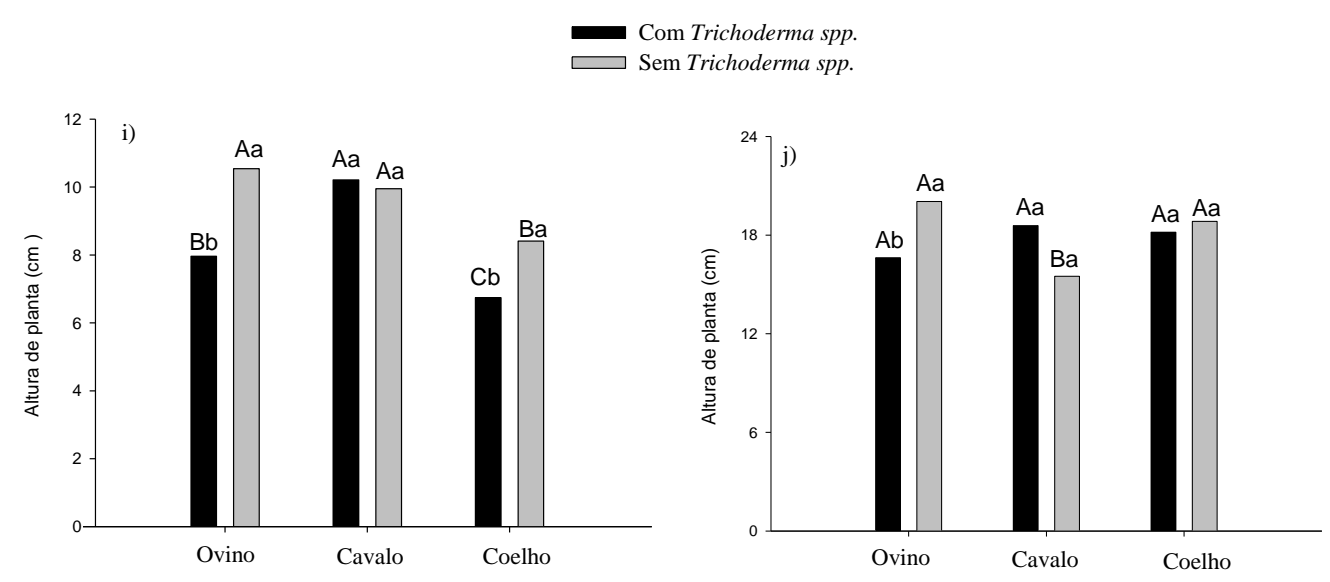

Figura 6. Altura de plantas de alface cultivadas em substratos base da criação de ovinos, cavalos e coelhos, com e sem Trichoderma spp., no primeiro ano de experimento (2015) (i); e (j), no segundo ano de experimento (2016). Médias seguidas por mesma letra maiúscula não diferem entre si entre os diferentes substratos. Médias seguidas por mesma letra minúscula não diferem entre si entre os tratamentos com e sem adição de Trichoderma pelo teste de Scott-Knott $(p<0,05)$.

Figure 6. Height of lettuce plants grown in substrate base of sheep, horse farms and rabbits with and without Trichoderma spp, the first year of experiment (2015) (i).; and (j), in the second year of experiment (2016). Means followed by the same capital letter do not differ between the different substrates. Means followed by the same lowercase letter do not differ between treatments with and without addition of Trichoderma spp. by the Scott-Knott test $(p<0.05)$.

No segundo ano de condução do experimento, houve interação entre os substratos base e o fungo para o número de folhas por plantas (Figura 7l). A associação do substrato base da criação de ovinos com o fungo resultou em diminuição de $37 \%$ no número de folhas por plantas. PEIXOTO \& PEIXOTO (2009) afirmam que as folhas são a referência de produção de matéria seca através da fotossíntese, sendo 0 restante da planta dependente da exportação dessa fitomassa. Os resultados deste estudo estão de acordo com o autor, pois no segundo ano de experimento o substrato a base da criação de cavalos associado ao fungo Trichoderma spp., teve um incremento de $24 \%$ no número de folhas por planta, refletindo nos maiores valores encontrados para massa seca (Figura 8). O uso do substrato base da criação de coelhos, associado com o fungo, não influenciou no número de folhas por planta de alface. INBAR et al. (1994) observaram aumento de área foliar em plântulas cultivadas em substrato tratado com o isolado de T. harzianum.

No primeiro ano de condução do experimento, não houve interação significativa entre os substratos base utilizados e o fungo. A massa seca de folhas foi $53 \%$ maior no substrato base da criação de cavalos, em comparação ao substrato base da criação de ovinos, e 127\% superior em comparação ao substrato base da criação de coelhos (Figura 8m).

No segundo ano de experimento, verificou-se que a utilização do fungo Trichoderma spp. reduziu a massa seca de folhas de alface em $29 \%$ (Figura 8 n). A associação do substrato base da criação de ovinos com o fungo reduziu em $87 \%$ a massa seca de folhas de plantas de alface. Para o substrato base da criação de cavalos, a associação com o fungo representou um incremento de $147 \%$ na massa seca de folhas. A associação do substrato base da criação de coelhos com o fungo não interferiu na massa seca de folhas de alface. De acordo com BUCIO et al. (2015), o efeito do isolado do fungo não contribuiu para uma maior produtividade das plantas. Pesquisas recentes sugerem que algumas combinações do Trichoderma com outros microrganismos podem melhorar o crescimento das plantas (COLLA et al. 2015). Uma combinação de $T$. atroviride e Bacillus subtilis promoveu melhor desenvolvimento de feijão em termos de massa seca de plantas, com $43 \%$ sobre o controle, $2 \%$ sobre o Trichoderma isolado e $34 \%$ para $B$. subtilis isolado (YOBO et al. 2011). 

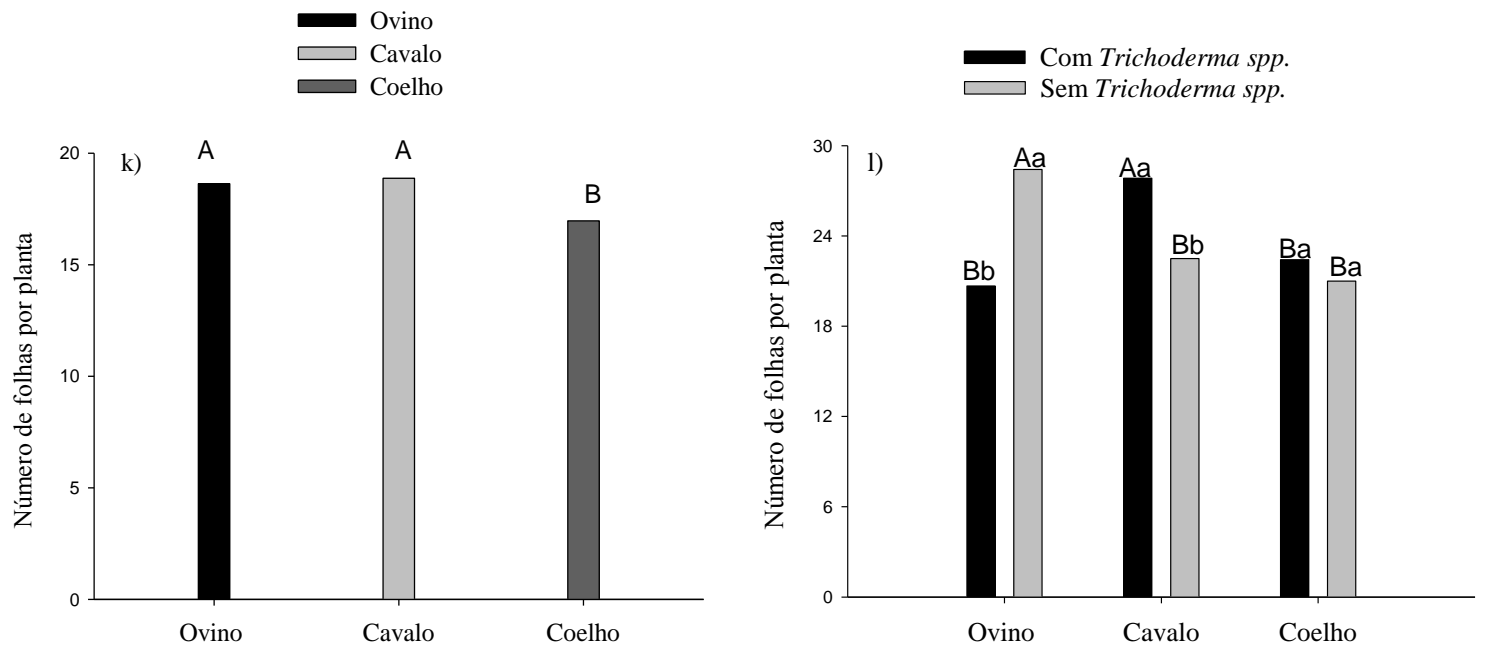

Figura 7. Número de folhas por planta de alface cultivadas em substratos base da criação de ovinos, cavalos e coelhos, com e sem Trichoderma spp., no primeiro ano de experimento (2015) (k); e (I), no segundo ano de experimento (2016). Médias seguidas por mesma letra maiúscula não diferem entre si entre os diferentes substratos. Médias seguidas por mesma letra minúscula não diferem entre si entre os tratamentos com e sem adição de Trichoderma pelo teste de ScottKnott $(p<0,05)$.

Figure 7. Number of leaves per lettuce plant cultivated on the basis substrates of sheep, horse farms and rabbits, with and without Trichoderma spp., the first year of experiment (2015) (k).; and (I), in the second year of experiment (2016). Means followed by the same capital letter do not differ between the different substrates. Means followed by the same lowercase letter do not differ between treatments with and without addition of Trichoderma spp. by the Scott-Knott test $(p<0.05)$.
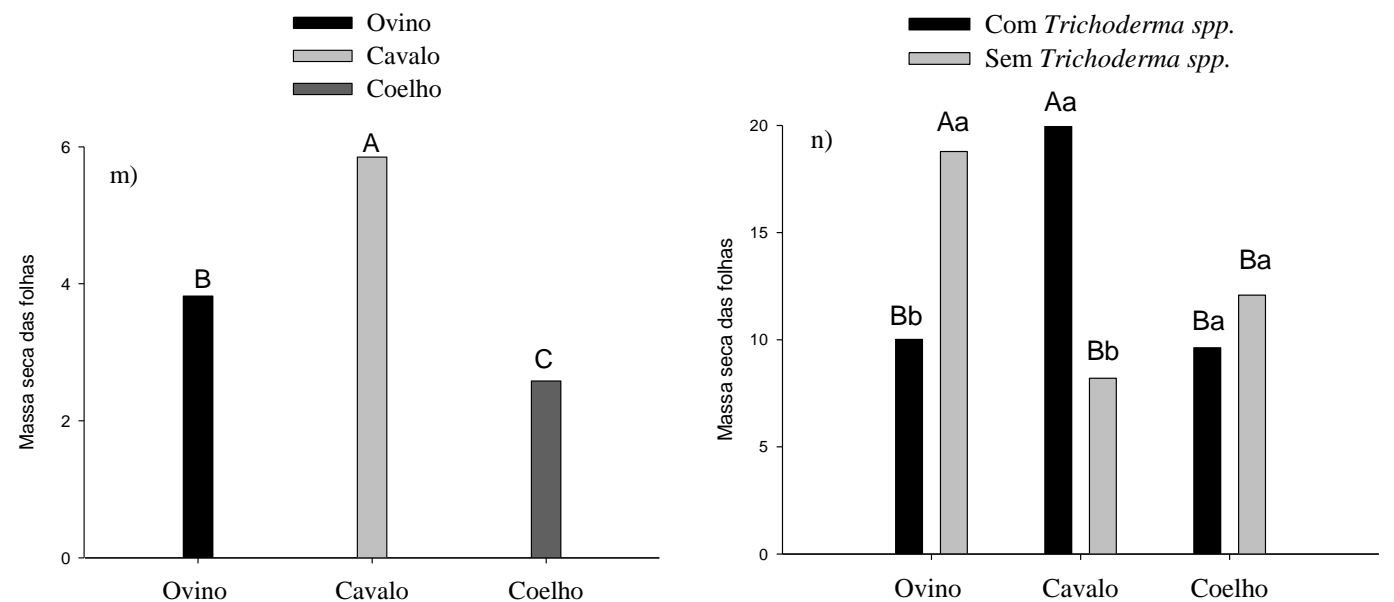

Figura 8. Massa seca das folhas de alface cultivadas em substratos base da criação de ovinos, cavalos e coelhos, com e sem Trichoderma spp., no primeiro ano de experimento (2015) (m); e (n), no segundo ano de experimento (2016). Médias seguidas por mesma letra maiúscula não diferem entre si entre os diferentes substratos. Médias seguidas por mesma letra minúscula não diferem entre si entre os tratamentos com e sem adição de Trichoderma spp.pelo teste de Scott-Knott $(p<0,05)$.

Figure 8. Dry mass of lettuce leaves grown on the basis substrates of sheep, horse farms and rabbits, with and without Trichoderma spp., the first year of experiment (2015) (m).; and (n), in the second year of experiment (2016). Means followed by the same capital letter do not differ between the different substrates. Means followed by the same lowercase letter do not differ between treatments with and without addition of Trichoderma spp. by the Scott-Knott test $(p<0.05)$. 


\section{CONCLUSÃO}

O fungo Trichoderma spp. sobrevive durante o processo de vermicompostagem de resíduos de criação de animais, tendo efeito sobre a densidade úmida e seca dos substratos a base da criação de ovino, de coelhos e de cavalos.

A utilização de Trichoderma spp. não teve efeito nos teores de fósforo, magnésio e matéria orgânica. Reduziu o teor de Cálcio dos substratos testados e aumentou os teores de Potássio, sendo mais responsiva no substrato a base da criação de coelhos.

Os dados obtidos mostram que o substrato que proporcionou 0 melhor crescimento $e$ desenvolvimento de plantas de alface foi a base de resíduos de criação de cavalos, sendo favorecida pela presença de Trichoderma spp. no segundo ano de cultivo.

\section{REFERÊNCIAS}

AIRA M et al. 2007. Eisenia fetida (Oligochaeta: Lumbricidae) modifies the structure and physiological capabilities of microbial communities improving carbon mineralization during vermicomposting of pig manure. Microbial Ecology 54: 662-671.

ALTOMARE CG et al. 1999. Solubilization of phosphates and micronutrients by the plant-growth promoting and biocontrol fungus Trichoderma harzianum Rifai 1295-22. Applied and Environmental Microbiology 65: 2926-2933.

AMORIM AC et al. 2005. Compostagem e vermicompostagem de dejetos de caprinos: efeito das estações do ano. Engenharia Agrícola 25: 57-66.

ARAÚJO NETO SE de. et al. 2009. Produção de muda orgânica de pimentão com diferentes substratos. Ciência Rural 39: 1408-1413.

BASSACO AC. 2014. Uso de resíduos de origem animal biotransformados na produção de mudas de alface. Dissertação. (Mestrado em Agrobiologia). Santa Maria: UFSM. 49p.

BROTMAN Y et al. 2010. Trichoderma. Current Biology 20: 390-391.

BUCIO JL et al. 2015. Trichoderma as biostimulant: exploiting the multilevel properties of a plant beneficial fungus. Scientia Horticulturae 196: 109-123.

BUSATO JG et al. 2012. Changes in labile phosphorus forms during maturation of vermicompost enriched with phosphorus-solubilizing and diazotrophic bacteria. Bioresource Technology 110: 390-395.

COLLA G et al. 2015. Co-inoculation of Glomus intraradices and Trichoderma atroviride acts as a biostimulant to promote growth, yield and nutrient uptake of vegetable crops. Journal of the Science of Food and Agriculture 95: 17061715.

CQFS-RS/SC. 2004. Comissão de Química e Fertilidade do Solo. Manual de adubação e calagem para os Estados do Rio Grande do Sul e Santa Catarina. 10.ed. Porto Alegre: Sociedade Brasileira de Ciência do Solo. 400p.

COTTA JAO et al. 2015. Compostagem versus vermicompostagem: comparação das técnicas utilizando resíduos vegetais, esterco bovino e serragem. Engenharia Sanitária e Ambiental 20: 65-78.

DINIZ KA et al. 2006. Húmus como substrato para a produção de mudas de tomate, pimentão e alface. Bioscience Journal 22: 63-70.

DOMINGUEZ J. 2004. State of the art and new perspectives on vermicomposting Research. In: EDWARDS CA. (Ed.). Earthworm ecology. $2^{\text {nd }}$ ed. Boca Raton: CRC Press. p. 401-424.

DURIGON MR et al. 2014. Adubações orgânicas e mineral e controle biológico sobre a incidência de podridões de colmo e produtividade de milho. Semina: Ciências Agrárias 35: 1249-1256.

FERMINO MH. 2003. Métodos de análises para caracterização física de substratos para plantas. Tese. (Doutorado em Fitotecnia). Porto Alegre: UFRGS. 104p.

FERREIRA DF. 2011. Sisvar: a computer statistical analysis system. Ciência e Agrotecnologia 35: 1039-1042.

GARD P et al. 2006. Vermicomposting of different types of waste using Eisenia foetida: A comparative study. Bioresource Technology 97: 391-395.

GONZALEZ JAZ et al. 2009. Acúmulo de ácido oxálico e cristais de cálcio em ectomicorrizas de eucalipto: II - formação de cristais de oxalato de cálcio induzida por fungos ectomicorrízicos em raízes laterais finas. Revista Brasileira de Ciência do Solo 33: 555-562.

HARMAN GE. 2000. Myth and dogmas of biocontrol changes in perceptions derived from research on Trichoderma harzianum T- 22. Plant Disease 84: 377-393.

HOFFMANN G. 1970. Verbindliche Metroden zur Untersuchung von TKS und Garterischen Erden. Mittelungen der VSLUFA 6: 129-153.

INBAR MJ et al. 1994. Plant growth enhancement and disease control bay Trichoderma harzianum in vegetable seedlings grown under commercial conditions. European Journal of Plant Pathology 100: 337-346.

JONES RW et al. 1988. Plant growth response to the phytotoxin viridiol produced by the fungus Gliocladium virens. Weed Science 36: 683-687.

KUBICEK CP et al. 2008. Fungal genus Hypocrea/Trichoderma from barcodes to biodiversity. Journal of Zhejiang University. Science. B. 9: 753-763.

LAZCANO C et al. 2008. Comparison of the effectiveness of composting and vermicomposting for the biological stabilization of cattle manure. Chemosphere 72: 1013-1019. 
LORES $\mathrm{M}$ et al. 2006. Using FAME profiles for the characterization of animal wastes and vermicomposts. Soil Biology and Biochemistry 38: 2993-2996.

MAENZ DD \& CLASSEN HL. 1998. Phytase activity in the small intestinal brush border membrane of the chicken. Poultry Science 87: 557-563.

MANSELL GP et al. 1981. Plant availability of phosphorous in dead herbage ingested by surface casting earthworms. Soil Biology \& Biochemistry 13: 163-167.

MORALES DA et al. 2013. Utilização dos Diferentes Vermicompostos Produzidos a Partir de Resíduos da Estação de Tratamento de Efluentes como Substrato para Produção de Mudas de Alface. Ciência e Natura 35: 55-63.

PEIXOTO CP \& PEIXOTO MFSP. 2009. Dinâmica do crescimento vegetal: princípios básicos. In: CARVALHO CAL et al. Tópicos em ciências agrárias. Cruz das Almas: Nova Civilização. p. 37-53.

PRATES HS et al. 2007. Composição mineral de mudas cítricas com aplicações de Trichoderma spp. São Paulo: IPNI. p. 4-5. (Informações Agronômicas no 118).

SATCHELL JE \& MARTIN K. 1984. Phosphate activity in earthworm faeces. Soil Biology and Biochemistry 16: $191-194$.

SILVA AC \& AGUIAR IJA. 2001. Micromorfologia da degradação de madeira da espécie amazônica Hura crepitans L. por fungos lignolíticos pertencentes a classe Hymenomycetes. Acta Amazonica 31: 397-418.

SOUZA EGF et al. 2013. Emergência e desenvolvimento de mudas de tomate IPA 6 em substratos, contendo esterco ovino. Revista Ceres 60: 902-907.

TAMAI MA et al. 2002. Avaliação de fungos entomopatogênicos para o controle de Tetranychus urticae Koch (Acari: Tetranychidae). Arquivo do Instituto Biológico 69: 77-84.

TEDESCO MJ et al. 1995. Análise de solo, plantas e outros materiais. 2.ed. Porto Alegre: UFRGS. 147p. (Boletim técnico, 5).

VINALE F et al. 2008. Trichoderma-plant-pathogen interactions. Soil Biology \& Biochemistry 40:1-10.

WANG $Y$ et al. 2005. Effect of cyadox on growth and nutrient digestibility in weanling pigs. South African Journal of Animal Science 35: 117-125.

WIETHAN MMS. 2015. Vermicompostagem e desenvolvimento inicial de alface em doses superiores de Trichoderma. Dissertação (Mestrado em Agrobiologia). Santa Maria: UFSM. 53p.

YOBO KS et al. 2011. Effects of single and combined inoculations of selected Trichoderma and Bacillus isolates on growth of dry bean and biological control of Rhizoctonia solani damping-off. African Journal of Biotechnology 10: 87468756 . 